\title{
Dietary patterns in UK adolescents obtained from a dual-source FFQ and their associations with socio-economic position, nutrient intake and modes of eating
}

\author{
Kate Northstone*, Andrew DAC Smith, Victoria L Cribb and Pauline M Emmett \\ School of Social and Community Medicine, University of Bristol, Oakfield House, Oakfield Grove, \\ Bristol BS8 2BN, UK
}

Submitted 27 June 2012: Final revision received 16 April 2013: Accepted 8 May 2013: First published online 20 June 2013

\begin{abstract}
Objective: To derive dietary patterns using principal components analysis from separate FFQ completed by mothers and their teenagers and to assess associations with nutrient intakes and sociodemographic variables.

Design: Two distinct FFQ were completed by 13-year-olds and their mothers, with some overlap in the foods covered. A combined data set was obtained.

Setting: Avon Longitudinal Study of Parents and Children (ALSPAC), Bristol, UK. Subjects: Teenagers ( $n$ 5334) with adequate dietary data.

Results: Four patterns were obtained using principal components analysis: a 'Traditional/health-conscious' pattern, a 'Processed' pattern, a 'Snacks/sugared drinks' pattern and a 'Vegetarian' pattern. The 'Traditional/health-conscious' pattern was the most nutrient-rich, having high positive correlations with many nutrients. The 'Processed' and 'Snacks/sugared drinks' patterns showed little association with important nutrients but were positively associated with energy, fats and sugars. There were clear gender and sociodemographic differences across the patterns. Lower scores were seen on the 'Traditional/health conscious' and 'Vegetarian' patterns in males and in those with younger and less educated mothers. Higher scores were seen on the 'Traditional/health-conscious' and 'Vegetarian' patterns in girls and in those whose mothers had higher levels of education.

Conclusions: It is important to establish healthy eating patterns by the teenage years. However, this is a time when it is difficult to accurately establish dietary intake from a single source, since teenagers consume increasing amounts of foods outside the home. Further dietary pattern studies should focus on teenagers and the source of dietary data collection merits consideration.
\end{abstract}

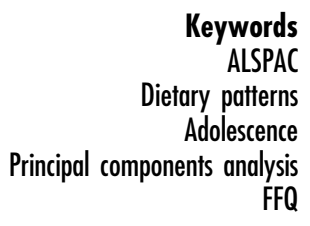

Adolescence is an important stage in the life course. It is a period of transition from childhood towards adulthood, not just physically through the mechanics of puberty, but also behaviourally as individuals begin to exert their independence from their parents. Healthy eating patterns established during this time are particularly important as they are likely to track into adulthood ${ }^{(1)}$. Diet is intrinsically linked to a large number of health outcomes and improved dietary intake can help reduce the risk of many diseases, particularly those related to obesity, such as heart disease, diabetes and cancer ${ }^{(2,3)}$.

Examining overall dietary patterns, as opposed to individual food groups and/or nutrients, has become increasingly popular. It is now established as an appropriate means of investigating the relationships between diet and health outcomes as foods are always eaten in combination. Principal components analysis (PCA), a data reduction technique, uses the correlations between food consumption variables to derive linear combinations of those variables. It is a powerful and commonly used method of deriving dietary patterns. It has been performed primarily in adults and young children; to our knowledge, only five papers have studied dietary patterns obtained using PCA specifically in adolescents ${ }^{(4-8)}$. These studies have been performed in Greece ${ }^{(4)}$, Spain ${ }^{(5)}$, Australia $^{(6,7)}$ and the $\mathrm{USA}^{(8)}$, with no studies carried out in a UK population.

An added complication in the accurate assessment of dietary intake using FFQ in this age group is that parents may not be fully aware of all the foods consumed by their teenagers away from home ${ }^{(9)}$ and teenagers may not be able to accurately record the details of all the foods provided for them at home ${ }^{(10)}$; therefore a combined approach may be the best option ${ }^{(11)}$. In the Avon Longitudinal Study of Parents and Children (ALSPAC) we have previously always asked parents (usually the mother) to 
complete the FFQ on behalf of the child. In adolescence, it is important to capture both the parent's and the teenager's reports of what the teenager is consuming; therefore, in the present study, dietary information was collected from both and a combination of the data was used to derive dietary patterns.

We hypothesised that distinct dietary patterns could be extracted from this combined data set as we have done previously using only parent-completed $\mathrm{FFQ}^{(12,13)}$. The current paper reports on the dietary patterns of these 13-year-old children obtained using PCA. To test the validity of the extracted patterns we examine the associations between dietary pattern scores and estimated nutrient intakes, hypothesising that patterns deemed to be healthier are more nutrient-rich. We also investigate whether there are differences in dietary pattern scores according to sociodemographic factors. We expect that any associations evident will be similar to those we have previously shown during childhood; for example, that healthier patterns are consumed by the more socially advantaged $^{(12,13)}$.

\section{Methods}

ALSPAC is an ongoing population-based study investigating the influence of environment and genetics on development and health ${ }^{(14)}$. ALSPAC recruited 14541 pregnant women resident in the (former) Avon Health Authority, in South West England, who had expected dates of delivery between 1 April 1991 and 31 December 1992; 13988 children were alive at 1 year. When the oldest children were approximately 7 years of age, the initial sample was bolstered with eligible cases that failed to join the study originally; the number of additional children who enrolled was 548, therefore 14536 children in total formed the baseline for the present study. The primary method of data collection was via self-completion questionnaires, completed by the mother during pregnancy and at various time points afterwards. These were supplemented by questionnaires completed by the children themselves at regular intervals from the age of 7 years. More information is available on the ALSPAC website (http://www.bristol.ac.uk/ alspac). Ethical approval for the study was obtained from the ALSPAC Law and Ethics Committee and the Local Research Ethics Committees.

The primary carer, usually the mother figure of the study teenager, was sent a questionnaire when their study child was 157 months ( $13 \cdot 1$ years) of age. This included an FFQ which asked about the frequency of consumption 'nowadays' by her teenager of eighty different foods and drinks (see Appendix). The mother was asked specifically to respond to the questions only regarding the foods provided by her, including packed lunches but excluding school dinners and other foods consumed outside the home. The FFQ was adapted from that previously used in mothers when they were pregnant. This has been shown to produce mean nutrient intakes ${ }^{(15)}$ similar to those obtained for women in the National Diet and Nutritional Survey for British adults ${ }^{(16)}$. The specific question on the frequency of oily fish consumption has also been validated by comparison with the erythrocyte fatty acid composition of pregnancy blood samples. The erythrocyte DHA content increased significantly with increasing frequency of consumption of oily fish $(P<0 \cdot 001)^{(17)}$.

Each study teenager was sent an FFQ to complete at the same time ( $86 \cdot 0 \%$ were completed within 1 month of each other). The teenagers were asked about their consumption of foods 'nowadays' that were not included in the mother's FFQ; that is, foods consumed as part of school dinners, food bought outside school and also additional snacks and drinks. The child's questionnaire was kept short, only covering foods not in the parental sphere, so as not to place too great a burden on the child. There was some overlap with the mother's FFQ; for example, the teenagers were asked about the foods contained within their packed lunches. Fifty-four food groups were included in this FFQ, although some foods were asked about in more than one context (see Appendix). For example, teenagers were asked about the chips they consumed as part of school dinners and those bought outside school, while the mothers were asked about chips provided at home. All dietary data were collected between 2004 and 2006 and the complete text of all questionnaires can be found on the ALSPAC website. Details of how these variables were treated are given below.

The majority of questions in both FFQ were posed on an ordinal scale, which differed slightly from section to section. All variables were converted to the frequency of consumption per week, as follows: 'never or rarely' $=0$, 'once a month or less' $=0 \cdot 25$, 'once in 2 weeks' $=0 \cdot 5$, 'once a week' $=1$, ' $1-3$ times a week' $=2$, ' $2-3$ times a week' $=2 \cdot 5$, ' $4-5$ times a week' $=4 \cdot 5,4-7$ times a week' $=5.5$ and 'more than once a day' $=10$ (note that not all options were available for all questions). The frequencies of consumption of bread, fruit, tea and coffee were measured on continuous scales as the number of slices, the number of pieces and the number of cups per day, respectively.

The food items from the two FFQ were combined together to create sixty-two food groups (see Appendix). If foods were asked about in both FFQ, or in more than one place, then the following rules were applied to obtain the frequency of consumption of those foods:

1. If a food item was included in both $F F Q$, then the average frequency of consumption was taken from the two sources.

2. If two or more food items were combined into a single question in one FFQ but asked about in separate questions in the other, the frequencies were split between each food item to enable combination 
(e.g. rice and potatoes were asked about in one question in the teenager's FFQ but were separate items in the mother's FFQ).

3. Where food items were asked about in several different sections of the same FFQ, the highest value was taken. For example, the teenager's FFQ asked about crisps in (i) packed lunches, (ii) bought outside school and (iii) total consumption. The frequency of consumption in packed lunches and bought outside school was combined and the highest value between this and the total reported frequency was taken.

A number of sociodemographic and lifestyle variables were considered as potentially being associated with dietary patterns, as we have shown at earlier time points ${ }^{(13)}$. Maternal age and education, and ethnicity, were recorded via self-completion questionnaire during pregnancy. The gender of the teenager was noted at birth. Maternal employment status (current employment regardless of full or part time) and whether she lived with a partner were both recorded via self-completion questionnaires when the study children were 11 and 12 years of age, respectively. The number of older and younger siblings living with the teenager was recorded when they were 11.5 years of age.

Daily nutrient intakes were estimated from the combined FFQ using the 5th edition of McCance and Widdowson's The Composition of Foods ${ }^{(18)}$ and supplements ${ }^{(19,20)}$. Additional up-to-date nutrient information was obtained from the National Diet and Nutrition Survey database and manufacturers' information. Standard portion sizes were assumed based on food records collected at $13 \cdot 5$ years ${ }^{(11)}$; these were also used to inform the selection of foods to include in each food group for the nutrient calculations.

\section{Statistical methods}

In order to compare the teenager's report of their frequency of consumption with their mother's report, Pearson's correlations were calculated for selected foods (those where the teenager report would theoretically have been included in the maternal report and therefore some level of agreement would be expected).

The sixty-two food frequency variables were entered into a PCA with varimax rotation ${ }^{(21,22)}$. Our methods have been described in detail elsewhere ${ }^{(12,13)}$. Briefly, PCA exploits the structure in the correlation between variables to create factors that explain as much variation in the data as possible. The components that are derived are linear combinations of the food frequency variables, and each individual has a resulting score for each component. The factor loadings, which are the correlations between the components and each variable, indicate which foods are important for each component and are used to help describe the resulting dietary patterns. Loadings above 0.30 are highlighted as being particularly important in assisting in labelling the patterns. The choice of the number of components to retain was based on the scree plot $^{(23)}$ together with the interpretability of the resulting components. Teenagers who had more than ten missing values in either FFQ were excluded from the PCA ( $n$ 785); those with ten or fewer had missing values put to zero, thereby assuming that they did not consume those foods.

Linear regression was used to examine the associations between the component scores and the sociodemographic variables, the association for each variable being adjusted for all others in order to determine independent relationships. The component scores were standardised by dividing by their standard deviation in order to facilitate comparisons between associations with different dietary patterns. Spearman's correlation coefficients were calculated to measure the associations between the dietary pattern scores and the respective nutrient intakes. Additionally, partial correlation coefficients were calculated, adjusting for energy intake. The proportion of variance explained by the dietary pattern scores was obtained for both absolute and energy-adjusted nutrient intakes by summing the squares of the correlations with each dietary pattern for each nutrient. Adjusted parameter estimates and $95 \%$ confidence intervals are presented throughout. All analyses were performed using the statistical software package Stata version $11 \cdot 1$.

\section{Results}

A total of 7152 mothers and 7119 teenagers returned their respective questionnaires at $13 \cdot 1$ years. Both sources of data were available for $6203(42 \cdot 7 \%$ of baseline) teenagers and of these $5418(87 \cdot 3 \%)$ had sufficient dietary data available for analysis. Table 1 presents the correlations for foods where both the teenager and the mother reported intakes. The correlations ranged from $0 \cdot 183$ for meat pies/pasties to 0.528 for fruit, although all were significant at $P<0 \cdot 001$.

Four principal components were retained, explaining $20 \cdot 8 \%$ of the variance in food frequencies of the sample. The factor loadings for each dietary pattern are shown in Table 2. The first component had high positive loadings

Table 1 Correlations between maternal and teenage reports ( $n$ 5418) of the frequency of consumption of selected foods; Avon Longitudinal Study of Parents and Children (ALSPAC), Bristol, UK, 2004-2006

\begin{tabular}{lc}
\hline Food group & Correlation \\
\hline Meat pies/pasties & 0.183 \\
Salad & 0.352 \\
Lunchbox snacks & 0.212 \\
Yoghurts/fromage frais & 0.309 \\
Cakes/buns & 0.224 \\
Flavoured milk drinks & 0.403 \\
Fruit juice & 0.510 \\
Water & 0.486 \\
Fruit & 0.528 \\
\hline
\end{tabular}

All correlations significant at $P<0.001$. 
Table 2 Factor loadings for the four dietary patterns identified by principal components analysis using two combined FFQ assessing diet in 13-year-olds ( $n$ 5418); Avon Longitudinal Study of Parents and Children (ALSPAC), Bristol, UK, 2004-2006

\begin{tabular}{|c|c|c|c|c|}
\hline \multirow[b]{2}{*}{ Food item } & \multicolumn{4}{|c|}{ Factor (variance explained) } \\
\hline & $\begin{array}{c}\text { 'Traditional/health-conscious' } \\
(6.61 \%)\end{array}$ & $\begin{array}{c}\text { 'Processed' } \\
(6 \cdot 15 \%)\end{array}$ & $\begin{array}{c}\text { 'Snacks/sugared drinks' } \\
(4 \cdot 25 \%)\end{array}$ & $\begin{array}{l}\text { 'Vegetarian' } \\
(3.79 \%)\end{array}$ \\
\hline Meat dishes & 0.304 & 0.176 & -0.094 & -0.642 \\
\hline Cold meats & 0.012 & -0.006 & $0 \cdot 153$ & -0.414 \\
\hline Poultry & $0 \cdot 268$ & -0.031 & 0.037 & -0.606 \\
\hline Meat sausages/burgers & $-0 \cdot 119$ & 0.554 & -0.038 & $-0 \cdot 188$ \\
\hline Meat pies/pasties & 0.028 & 0.506 & 0.006 & -0.095 \\
\hline Offal & 0.088 & $0 \cdot 010$ & 0.023 & -0.087 \\
\hline Fish & 0.431 & -0.002 & -0.044 & -0.077 \\
\hline Chicken/turkey in crispy coating & -0.249 & 0.419 & -0.004 & $-0 \cdot 122$ \\
\hline White fish in breadcrumbs/batter & 0.070 & 0.338 & -0.080 & $-0 \cdot 109$ \\
\hline Eggs & 0.332 & $0 \cdot 226$ & -0.081 & $0 \cdot 140$ \\
\hline Cheese & 0.254 & 0.046 & 0.083 & 0.245 \\
\hline Rice & 0.488 & $0 \cdot 124$ & $-0 \cdot 120$ & $-0 \cdot 103$ \\
\hline Pasta & 0.403 & $0 \cdot 141$ & -0.061 & 0.058 \\
\hline Pizza & 0.016 & 0.577 & -0.012 & $0 \cdot 185$ \\
\hline Baked beans/tinned pasta & 0.015 & 0.535 & -0.075 & 0.022 \\
\hline Fried food & 0.054 & 0.363 & $-0 \cdot 115$ & 0.034 \\
\hline Raw fruit & 0.353 & $-0 \cdot 141$ & -0.053 & 0.082 \\
\hline Tinned fruit & $0 \cdot 115$ & $0 \cdot 148$ & 0.037 & 0.038 \\
\hline Salad & 0.583 & $-0 \cdot 125$ & -0.031 & 0.078 \\
\hline Peas & 0.430 & 0.077 & $0 \cdot 012$ & $-0 \cdot 117$ \\
\hline Sweetcorn & 0.466 & 0.123 & -0.020 & -0.038 \\
\hline Green vegetables & 0.635 & $-0 \cdot 164$ & 0.038 & $-0 \cdot 119$ \\
\hline Root vegetables & 0.641 & $-0 \cdot 142$ & $0 \cdot 106$ & $-0 \cdot 152$ \\
\hline Meat substitutes & 0.163 & 0.052 & 0.015 & 0.667 \\
\hline Vegetarian pies/pasties & 0.210 & 0.255 & -0.063 & 0.475 \\
\hline Nuts & 0.252 & -0.028 & 0.022 & 0.310 \\
\hline Pulses & 0.350 & -0.071 & -0.045 & 0.375 \\
\hline Potatoes & 0.433 & 0.098 & 0.021 & -0.203 \\
\hline Roast potatoes & $0 \cdot 115$ & 0.464 & -0.033 & -0.207 \\
\hline Chips & $-0 \cdot 193$ & 0.674 & 0.013 & 0.047 \\
\hline Crisps & -0.097 & 0.040 & 0.672 & 0.025 \\
\hline Biscuits & 0.069 & -0.082 & 0.779 & -0.014 \\
\hline Crispbreads & $0 \cdot 168$ & 0.030 & 0.031 & $0 \cdot 186$ \\
\hline Chocolate & 0.009 & -0.041 & 0.817 & 0.008 \\
\hline Sweets & -0.013 & $0 \cdot 170$ & 0.541 & 0.007 \\
\hline White bread (slices) & -0.239 & 0.258 & 0.003 & 0.010 \\
\hline Other bread (slices) & 0.290 & $-0 \cdot 311$ & $0 \cdot 124$ & 0.077 \\
\hline Butter/margarine & 0.034 & -0.015 & $0 \cdot 181$ & 0.058 \\
\hline Non-homemade sandwiches & 0.051 & 0.288 & -0.063 & 0.075 \\
\hline Lunchbox snacks & -0.083 & 0.235 & 0.088 & 0.064 \\
\hline Yoghurt/fromage frais & 0.278 & 0.019 & $0 \cdot 158$ & 0.030 \\
\hline Puddings & 0.333 & 0.366 & -0.104 & -0.036 \\
\hline Milk puddings/custard/mousse & 0.258 & 0.373 & 0.040 & 0.013 \\
\hline Ice cream & 0.065 & 0.260 & $0 \cdot 146$ & 0.071 \\
\hline Ice lollies & -0.003 & 0.316 & $0 \cdot 117$ & 0.094 \\
\hline Cakes/buns & $0 \cdot 193$ & 0.305 & $0 \cdot 146$ & 0.021 \\
\hline Ketchup/brown sauce & -0.028 & 0.407 & 0.012 & 0.065 \\
\hline Mayonnaise/salad cream/dressing & 0.273 & 0.101 & 0.052 & 0.063 \\
\hline Oat-based cereal & 0.228 & -0.026 & -0.031 & 0.019 \\
\hline Bran-based-cereal & 0.205 & $-0 \cdot 107$ & 0.080 & -0.025 \\
\hline Other cereal & -0.060 & 0.083 & 0.093 & -0.006 \\
\hline Cereal bars & -0.002 & $0 \cdot 133$ & 0.033 & $0 \cdot 128$ \\
\hline Full-fat milk & -0.010 & $0 \cdot 110$ & $0 \cdot 017$ & 0.015 \\
\hline Other milk & $0 \cdot 122$ & -0.061 & 0.069 & -0.004 \\
\hline Flavoured milk drinks & $0 \cdot 136$ & 0.129 & 0.247 & 0.041 \\
\hline Fruit juice & $0 \cdot 247$ & -0.028 & 0.006 & 0.093 \\
\hline Squash/cordial & -0.024 & -0.041 & 0.347 & -0.071 \\
\hline Water & 0.292 & $-0 \cdot 120$ & -0.033 & 0.061 \\
\hline Fizzy drinks & $-0 \cdot 106$ & $0 \cdot 265$ & 0.335 & -0.028 \\
\hline Tea/coffee & 0.074 & 0.044 & 0.129 & -0.023 \\
\hline Herbal tea & $0 \cdot 147$ & -0.028 & -0.054 & 0.072 \\
\hline Alcohol & $0 \cdot 107$ & 0.044 & 0.019 & 0.069 \\
\hline
\end{tabular}

Factor loadings greater than $10 \cdot 301$ are shown in bold. 
for meat, fish, eggs, cheese, rice, pasta, potatoes, vegetables, salad, fruit, pulses, brown and wholemeal bread, dairy-based desserts, puddings, salad dressings and water. It had high negative loadings for white bread and coated poultry products. This component was named the 'Traditional/health-conscious' pattern as it appeared to overlap with the 'Health conscious' and 'Traditional' patterns that we have previously described at younger ages $^{(12,13)}$. The second component had high loadings for processed meat, coated poultry and fish products, chips, roast potatoes, pizza, tinned pasta and baked beans, ketchup, sandwiches, cakes and buns, puddings and dairy-based desserts. There was a large negative loading on brown and wholemeal bread. This pattern was named 'Processed', in line with previous findings ${ }^{(12,13)}$. The next component had high loadings for crisps, biscuits, chocolate, sweets, squash and fizzy drinks. We chose to name this component the 'Snacks/sugared drinks' pattern. The final component had high positive loadings for vegetarian-style foods (such as meat substitutes, nuts and pulses) and high negative loadings for meats, and was therefore labelled the 'Vegetarian' pattern.

The associations between the dietary pattern scores and the sociodemographic variables are shown in Table 3 for the 3951 teenagers with complete data. Scores were higher on the 'Traditional/health-conscious' pattern for females, as levels of maternal education increased (all $P<0.001)$, and if mothers were not in employment $(P=0 \cdot 002)$. For the 'Processed' pattern scores were higher in males, if mothers were younger or less educated, and when two or more older or younger siblings were present (the majority $P<0 \cdot 001$ ). Scores on the 'Snacks/sugared drinks' pattern were higher in males, when mothers were younger or less educated (all $P<0.001)$, and in the presences of siblings, both younger and older $(P=0.006$ and $P=0 \cdot 011$, respectively). Teenagers with working mothers also scored higher on this pattern $(P=0 \cdot 002)$. Finally, the 'Vegetarian' pattern was strongly associated with being female and having a degree-educated mother (both $P<0 \cdot 001$ ). There was also some evidence to suggest that ethnicity was associated with the 'Snacks/sugared drinks' and 'Vegetarian' patterns, with white children scoring higher on the 'Snacks/ sugared drinks' pattern and non-white children scoring higher on the 'Vegetarian' factor pattern (both $P<0 \cdot 05$ ).

Table 4 shows the absolute and energy-adjusted correlations between the dietary pattern scores and estimated nutrient intakes. Strong positive correlations $(r>0.5)$ were evident between the 'Traditional/health conscious' pattern and the absolute intake of many of the nutrients including protein, fibre, $\mathrm{K}, \mathrm{Mg}, \mathrm{Zn}$, vitamin $\mathrm{C}$, folate and carotene. These correlations were robust to adjustment for energy, as the coefficients barely changed, showing this to be a nutrient-rich pattern. The 'Processed' pattern was positively correlated with absolute intakes of energy, fat, carbohydrates and $\mathrm{Na}$. After adjustment for energy intake, the highest correlations were seen between this pattern and polyunsaturated fat and $\mathrm{Na}(r=0 \cdot 409$ and $0 \cdot 379$, respectively). Strong positive correlations $(r>0 \cdot 5)$ were seen between the 'Snacks/sugared drinks' pattern and absolute intakes of energy, fat, carbohydrates and sugar. However, after energy adjustment negative associations emerged with protein, fibre, $\mathrm{K}, \mathrm{Fe}, \mathrm{Zn}$ and niacin (all $r<-0 \cdot 3$ ) and a positive association with sugar $(r=0.334)$. Finally, the 'Vegetarian' pattern did not show any strong associations with any of the absolute nutrient intakes. After energy adjustment, the largest correlations were seen with protein $(r=-0.453), \mathrm{Zn}(r=-0 \cdot 345)$ and niacin $(r=-0 \cdot 484)$. The proportion of the variation of absolute intakes was explained well by the dietary patterns for many nutrients, with over $50 \%$ explained for energy, protein, fibre, $\mathrm{K}, \mathrm{Mg}$, $\mathrm{Zn}$ and niacin after energy adjustment.

\section{Discussion}

In a contemporary cohort of 13-year-olds we have obtained four underlying dietary patterns using PCA: 'Traditional/ health-conscious', 'Processed', 'Snacks/sugared drinks' and 'Vegetarian'. Three of these patterns are similar to those we have previously reported in this cohort $^{(24)}$; however, this time a new pattern has emerged: the 'Snacks/sugared drinks' pattern. It is not clear whether this is due to the difference in input variables in the current analysis compared with those used previously or whether this is due to a genuine change in patterns of intake over time. We did not rely on parental report only, as we had in previous work, but questioned these older children directly about the foods they consumed and purchased outside the home via an FFQ designed for that purpose.

When we restricted the analysis to the data provided by the mothers only we obtained three patterns: 'Healthconscious', 'Processed' and 'Vegetarian'. These are much more in line with the patterns we obtained at 9 years of age $^{(24)}$. However, this restriction ignores foods consumed as school dinners or purchased outside the home. For many teenagers these foods contribute a substantial amount to their total intake and it is important that they are included. Furthermore, the mother's FFQ did not include questions on the consumption of squashes/cordials, carbonated drinks, crisps, biscuits, chocolate and sweets. These foods can be considered to be nonessential or non-core foods ${ }^{(25)}$ as they provide very few nutrients yet are high in energy and extremely palatable. All these foods loaded highly on the 'Snacks/sugared drinks' pattern. It was important therefore that we did not rely on the mothers' data alone.

There were reasonable levels of correlation between maternal and subject report of those foods that were asked of both mother and teenager (all $P<0 \cdot 0001$ ). However, the correlations were lowest for those items that could be eaten more readily outside the home (meat pies/pasties, lunchbox 
Table 3 Adjusted $^{*}$ associations (parameter estimates and $95 \%$ confidence intervals) between sociodemographic characteristics and standardised dietary pattern scores in $13-y e a r-o l d s$ ( $n$ 3951); Avon Longitudinal Study of Parents and Children (ALSPAC), Bristol, UK, 2004-2006

\begin{tabular}{|c|c|c|c|c|c|c|c|c|c|}
\hline \multirow[b]{2}{*}{ Characteristic } & \multirow[b]{2}{*}{$n$} & \multicolumn{2}{|c|}{ 'Traditional/health-conscious' } & \multicolumn{2}{|c|}{ 'Processed' } & \multicolumn{2}{|c|}{ 'Snacks/sugared drinks' } & \multicolumn{2}{|c|}{ ‘Vegetarian’ } \\
\hline & & Parameter estimate & $95 \% \mathrm{Cl}$ & Parameter estimate & $95 \% \mathrm{Cl}$ & Parameter estimate & $95 \% \mathrm{Cl}$ & Parameter estimate & $95 \% \mathrm{Cl}$ \\
\hline \multicolumn{10}{|l|}{ Gender } \\
\hline Male & 1916 & Ref. & & Ref. & & Ref. & & Ref. & \\
\hline $\begin{array}{l}\text { Female } \\
P\end{array}$ & 2035 & $\begin{array}{l}-0.148 \\
<0.001\end{array}$ & $0.090,0.207$ & $\begin{array}{l}-0.231 \\
<0.001\end{array}$ & $-0.288,-0.173$ & $\begin{array}{l}-0.140 \\
<0.001\end{array}$ & $-0.200,-0.081$ & $\begin{array}{l}-0.224 \\
<0.001\end{array}$ & $0 \cdot 164,0 \cdot 285$ \\
\hline \multicolumn{10}{|c|}{ Ethnicity of child } \\
\hline White & 3830 & Ref. & & Ref. & & Ref. & & Ref. & \\
\hline $\begin{array}{l}\text { Non-white } \\
P\end{array}$ & 121 & $\begin{array}{r}-0.049 \\
0.571\end{array}$ & $-0 \cdot 121,0 \cdot 220$ & $\begin{array}{r}-0.045 \\
0.601\end{array}$ & $-0.212,0 \cdot 123$ & $\begin{array}{r}-0.174 \\
0.048\end{array}$ & $-0.346,-0.001$ & $\begin{array}{r}-0.194 \\
0.030\end{array}$ & $0.019,0.370$ \\
\hline \multicolumn{10}{|c|}{ Maternal age (years) } \\
\hline 31 or more & 1564 & Ref. & & Ref. & & Ref. & & Ref. & \\
\hline $26-30$ & 1745 & -0.070 & $-0.138,-0.002$ & -0.080 & $0.013,0.146$ & -0.144 & $0.075,0.212$ & -0.072 & $-0.142,-0.002$ \\
\hline $21-25$ & 568 & -0.077 & $-0.176,0.022$ & $-0 \cdot 148$ & $0.051,0.245$ & -0.273 & $0.173,0.373$ & $-0 \cdot 136$ & $-0.238,-0.034$ \\
\hline Up to 20 & 74 & -0.060 & $-0.288,0 \cdot 168$ & $-0 \cdot 434$ & $0 \cdot 210,0.658$ & $-0 \cdot 261$ & $0.030,0.492$ & -0.044 & $-0 \cdot 279,0 \cdot 191$ \\
\hline$P$ & & $0 \cdot 208$ & & $<0.001$ & & $<0.001$ & & 0.052 & \\
\hline \multicolumn{10}{|c|}{ Maternal educationt } \\
\hline CSE & 397 & Ref. & & Ref. & & Ref. & & Ref. & \\
\hline Vocational & 266 & -0.220 & $0.074,0.366$ & $-0 \cdot 182$ & $-0.325,-0.038$ & $-0 \cdot 105$ & $-0.253,0.043$ & -0.096 & $-0.246,0.054$ \\
\hline O level & 1348 & -0.446 & $0.340,0.552$ & -0.304 & $-0.408,-0.200$ & -0.130 & $-0.237,-0.022$ & -0.023 & $-0.132,0.086$ \\
\hline A level & 1139 & $0 \cdot 714$ & $0.605,0.824$ & -0.470 & $-0.577,-0.362$ & -0.415 & $-0.525,-0.304$ & -0.079 & $-0.034,0.191$ \\
\hline $\begin{array}{l}\text { Degree } \\
P\end{array}$ & 801 & $\begin{array}{l}-0.908 \\
<0.001\end{array}$ & $0 \cdot 791,1 \cdot 026$ & $\begin{array}{l}-0.649 \\
<0.001\end{array}$ & $-0.764,-0.533$ & $\begin{array}{l}-0.628 \\
<0.001\end{array}$ & $-0.747,-0.509$ & $\begin{array}{l}-0.262 \\
<0.001\end{array}$ & $0.141,0.383$ \\
\hline \multicolumn{10}{|c|}{ Mother has a partner } \\
\hline Yes & 3776 & Ref. & & Ref. & & Ref. & & Ref. & \\
\hline No & 175 & $-0 \cdot 103$ & $-0.245,0.041$ & -0.020 & $-0 \cdot 121,0 \cdot 161$ & $-0 \cdot 138$ & $-0.283,0.006$ & -0.081 & $-0.228,0.066$ \\
\hline$P$ & & $0 \cdot 161$ & & $0 \cdot 780$ & & 0.061 & & 0.282 & \\
\hline \multicolumn{10}{|c|}{ Mother in employment } \\
\hline Yes & 3231 & Ref. & & Ref. & & Ref. & & Ref. & \\
\hline $\begin{array}{l}\text { No } \\
P\end{array}$ & 720 & $\begin{array}{r}-0.126 \\
0.002\end{array}$ & $0.048,0.204$ & $\begin{array}{r}-0.014 \\
0.716\end{array}$ & $-0.063,0.091$ & $\begin{array}{r}-0.129 \\
0.001\end{array}$ & $-0.208,-0.050$ & $\begin{array}{r}-0.010 \\
0.804\end{array}$ & $-0.070,0.091$ \\
\hline \multicolumn{10}{|l|}{ Older siblings } \\
\hline 0 & 2044 & Ref. & & Ref. & & Ref. & & Ref. & \\
\hline 1 & 1426 & -0.002 & $-0.074,0.069$ & -0.038 & $-0.032,0.109$ & -0.073 & $0.001,0.146$ & -0.028 & $-0.046,0.102$ \\
\hline 2 or more & 481 & -0.019 & $-0.120,0.083$ & $-0 \cdot 134$ & $0.034,0.234$ & $-0 \cdot 150$ & $0.047,0.252$ & -0.051 & $-0.053,0.156$ \\
\hline$P$ & & 0.935 & & 0.031 & & $0 \cdot 011$ & & 0.586 & \\
\hline \multicolumn{10}{|c|}{ Younger siblings } \\
\hline 0 & 1853 & Ref. & & Ref. & & Ref. & & Ref. & \\
\hline 1 & 1561 & -0.027 & $-0.046,0 \cdot 100$ & -0.011 & $-0.061,0.082$ & $-0 \cdot 117$ & $0.043,0.191$ & -0.021 & $-0.054,0.097$ \\
\hline 2 or more & 537 & -0.002 & $-0 \cdot 106,0 \cdot 102$ & $-0 \cdot 181$ & $0.079,0.283$ & -0.042 & $-0.063,0.147$ & -0.079 & $-0.028,0.186$ \\
\hline$P$ & & 0.700 & & 0.001 & & 0.006 & & 0.343 & \\
\hline
\end{tabular}

\section{Ref., referent category.}

tCSE (Certificate of Secondary Education) equivalent to full-time education up to age 16 years but at a lower level of achievement to $\mathrm{O}$ levels; $\mathrm{O}$ level equivalent to full-time education up to age 16 years; $\mathrm{A}$ leve equivalent to full-time education up to age 18 years. 
Table 4 Correlation coefficients between dietary pattern scores and daily absolute nutrient intakes and partial correlation coefficients between dietary pattern scores and daily nutrient intakes adjusting for energy intake in 13-year-olds ( $n$ 3902); Avon Longitudinal Study of Parents and Children (ALSPAC), Bristol, UK, 2004-2006

\begin{tabular}{|c|c|c|c|c|c|c|c|c|c|c|}
\hline \multirow[b]{2}{*}{ Nutrient } & \multicolumn{2}{|c|}{ 'Traditional/health-conscious' } & \multicolumn{2}{|c|}{ 'Processed' } & \multicolumn{2}{|c|}{ 'Snacks/sugared drinks' } & \multicolumn{2}{|c|}{ 'Vegetarian' } & \multicolumn{2}{|c|}{$\%$ of variance explained } \\
\hline & Absolute & Adjusted & Absolute & Adjusted & Absolute & Adjusted & Absolute & Adjusted & Absolute & Adjusted \\
\hline Energy & 0.208 & - & 0.649 & - & 0.584 & - & -0.092 & - & $81 \cdot 4$ & - \\
\hline Total fat & $0 \cdot 151$ & -0.209 & 0.662 & $0 \cdot 185$ & 0.579 & 0.068 & -0.067 & 0.076 & $80 \cdot 1$ & $8 \cdot 8$ \\
\hline Protein & 0.461 & 0.510 & 0.577 & $0 \cdot 154$ & 0.263 & -0.410 & -0.349 & -0.453 & $73 \cdot 6$ & $65 \cdot 7$ \\
\hline Monounsaturated fat & 0.118 & -0.280 & 0.680 & 0.270 & 0.579 & 0.079 & $-0 \cdot 119$ & $-0 \cdot 110$ & $82 \cdot 6$ & $17 \cdot 0$ \\
\hline Polyunsaturated fat & 0.248 & $0 \cdot 140$ & 0.695 & 0.409 & 0.346 & -0.240 & $0.006^{\star}$ & $0 \cdot 127$ & $66 \cdot 4$ & $26 \cdot 1$ \\
\hline Saturated fat & 0.088 & $-0 \cdot 300$ & 0.552 & -0.179 & 0.618 & 0.256 & -0.053 & 0.083 & $69 \cdot 7$ & $19 \cdot 4$ \\
\hline Carbohydrates & 0.159 & $-0 \cdot 118$ & 0.578 & $-0 \cdot 168$ & 0.613 & 0.240 & -0.048 & $0 \cdot 131$ & $73 \cdot 7$ & $11 \cdot 7$ \\
\hline Sugar & $0 \cdot 101$ & $-0 \cdot 140$ & $0 \cdot 397$ & -0.383 & 0.638 & $0 \cdot 334$ & $-0.018^{\star}$ & $0 \cdot 104$ & $57 \cdot 5$ & $28 \cdot 9$ \\
\hline Fibre & $0 \cdot 616$ & 0.644 & 0.299 & $-0 \cdot 166$ & $0 \cdot 178$ & -0.315 & 0.062 & 0.142 & $50 \cdot 4$ & $56 \cdot 2$ \\
\hline K & 0.538 & 0.626 & 0.509 & 0.032 & 0.293 & $-0 \cdot 345$ & $-0 \cdot 159$ & $-0 \cdot 144$ & $66 \cdot 0$ & $53 \cdot 3$ \\
\hline $\mathrm{Na}$ & 0.233 & $0 \cdot 101$ & $0 \cdot 700$ & $0 \cdot 379$ & 0.380 & $-0 \cdot 258$ & -0.098 & $-0.026^{\star}$ & $69 \cdot 8$ & $22 \cdot 1$ \\
\hline $\mathrm{Ca}$ & 0.313 & 0.253 & 0.477 & -0.087 & $0 \cdot 410$ & $-0 \cdot 119$ & 0.080 & 0.253 & $49 \cdot 9$ & $15 \cdot 0$ \\
\hline $\mathrm{Mg}$ & 0.541 & 0.667 & 0.387 & -0.314 & 0.337 & $-0 \cdot 312$ & $0.010^{*}$ & 0.139 & $55 \cdot 6$ & $66 \cdot 0$ \\
\hline $\mathrm{Fe}$ & 0.462 & 0.497 & 0.381 & -0.262 & 0.307 & $-0 \cdot 302$ & $-0.018^{*}$ & 0.080 & $45 \cdot 3$ & $41 \cdot 3$ \\
\hline $\mathrm{Zn}$ & 0.539 & 0.609 & 0.456 & -0.094 & 0.252 & -0.377 & -0.290 & -0.345 & $64 \cdot 6$ & $64 \cdot 1$ \\
\hline Vitamin C & 0.541 & 0.517 & 0.013 & -0.177 & -0.054 & -0.212 & 0.046 & 0.063 & $29 \cdot 8$ & $34 \cdot 7$ \\
\hline lodine & 0.363 & 0.326 & 0.436 & -0.179 & 0.429 & -0.071 & -0.052 & $-0.035^{\star}$ & $50 \cdot 9$ & $14 \cdot 5$ \\
\hline $\mathrm{Se}$ & 0.425 & 0.391 & 0.294 & -0.252 & $0 \cdot 198$ & -0.319 & -0.086 & -0.035 & $31 \cdot 4$ & 31.9 \\
\hline Folate & 0.571 & 0.580 & 0.330 & $-0 \cdot 106$ & $0 \cdot 176$ & -0.297 & $-0.007^{\star}$ & 0.055 & $46 \cdot 6$ & 43.9 \\
\hline Carotene & 0.641 & 0.622 & $0.000^{*}$ & -0.158 & $0.018^{*}$ & $-0 \cdot 129$ & -0.135 & -0.138 & $42 \cdot 9$ & $44 \cdot 7$ \\
\hline Retinol & 0.309 & 0.241 & $0 \cdot 314$ & $0.003^{*}$ & $0 \cdot 153$ & -0.201 & $0.031^{*}$ & 0.084 & $21 \cdot 8$ & $10 \cdot 6$ \\
\hline Vitamin E & 0.219 & 0.096 & 0.557 & 0.122 & 0.412 & -0.076 & 0.021 & 0.153 & $52 \cdot 8$ & $25 \cdot 3$ \\
\hline Thiamin & 0.472 & 0.464 & 0.417 & -0.052 & 0.233 & -0.288 & $0.002^{*}$ & 0.098 & $45 \cdot 1$ & $31 \cdot 1$ \\
\hline Niacin & 0.454 & 0.464 & 0.510 & 0.099 & 0.220 & -0.368 & -0.400 & -0.484 & $67 \cdot 5$ & $59 \cdot 5$ \\
\hline Riboflavin & 0.356 & 0.306 & 0.256 & -0.236 & 0.305 & -0.077 & 0.132 & 0.234 & $30 \cdot 2$ & $21 \cdot 0$ \\
\hline Vitamin $B_{6}$ & 0.433 & 0.407 & 0.513 & $0 \cdot 128$ & 0.227 & -0.285 & -0.328 & -0.362 & $60 \cdot 9$ & $39 \cdot 4$ \\
\hline Vitamin $\mathrm{B}_{12}$ & 0.469 & 0.431 & 0.408 & $0.042^{*}$ & $0 \cdot 161$ & -0.259 & -0.250 & -0.240 & $47 \cdot 5$ & $31 \cdot 2$ \\
\hline Vitamin D & 0.386 & 0.341 & 0.265 & -0.020 & 0.062 & -0.268 & -0.096 & -0.067 & $23 \cdot 2$ & $19 \cdot 3$ \\
\hline$n-3$ Fatty acids (from fish) & 0.346 & 0.334 & -0.052 & $-0 \cdot 102$ & $-0 \cdot 127$ & $-0 \cdot 186$ & $-0.001^{\star}$ & $-0.002^{\star}$ & $13 \cdot 9$ & $15 \cdot 7$ \\
\hline DHA (from fish) & 0.328 & 0.316 & $-0.054^{*}$ & $-0 \cdot 101$ & $-0 \cdot 127$ & $-0 \cdot 184$ & $-0.001^{*}$ & $0.002^{\star}$ & $12 \cdot 7$ & $14 \cdot 4$ \\
\hline EPA (from fish) & 0.320 & 0.311 & -0.072 & $-0 \cdot 113$ & $-0 \cdot 130$ & -0.178 & 0.015 & 0.012 & $12 \cdot 5$ & $14 \cdot 1$ \\
\hline
\end{tabular}

All correlations significant at $P<0.001$ except those marked * 
snacks and cakes/buns). The highest correlations were seen with the foods that are considered to be healthier. The low level of overlap between the two FFQ did not allow us to make a more formal comparison between parental and subject report. Other studies have shown relatively low levels of agreement in younger children ${ }^{(26-28)}$. A recent Swedish study reported that 10-12-year-old children generally agreed with their parent's report of their meal patterns but differences were evident regarding the consumption of sweets and chocolate, with the children reporting less frequent consumption ${ }^{(28)}$. Further research is required in adolescents to determine whether they can accurately report their dietary intake. It is important to capture all sources of food at this age. The mother is still the primary provider for her 13-year-old child but the child is likely to purchase foods outside the home and consume foods at school that the mother is not aware of. For this reason we feel our approach of using both parent- and child-completed FFQ is justified.

Five other studies to date have examined dietary patterns in adolescents ${ }^{(4-8)}$. Generally, the patterns obtained in these studies differ from those we report here. For some this may be due to cultural differences, such as those from Greece $^{(4)}$ and Spain ${ }^{(5)}$, but it may also be due to the fact that adolescents were included in a wider age group: 12-17-year-olds ${ }^{(4)}, 2-24$-year-olds ${ }^{(5)}$ and $12-18$-year-olds ${ }^{(7)}$. It is quite possible that dietary patterns will change over these periods and this makes comparisons with a much narrower age range difficult. An American study of 13-year-olds identified four patterns named 'vegetable', 'fruit', 'sweet/salty snack food' and 'starchy food' ${ }^{(8)}$ with a few similarities to those reported here. The most comparable patterns were obtained from 14-year-olds taking part in the Australian Raine Study ${ }^{(6)}$. Two patterns were obtained: 'Western' and 'Healthy', and the foods loading highly on these patterns are very similar to those associated with our 'Processed' and 'Traditional/ health-conscious' patterns respectively. In these studies the adolescents provided the information on their dietary intake, with the exception of the Raine Study which sent the questionnaire to the main carer with instructions to complete the dietary sections in association with the study adolescent ${ }^{(6)}$.

Clear gender and sociodemographic differences in the dietary patterns in ALSPAC have been reported previously in the ALSPAC children ${ }^{(12,13)}$ and similar differences are evident at 13 years of age. In particular, higher scores on the less healthy patterns ('Processed' and 'Snacks/sugared drinks') were seen in males and those with younger and less educated mothers. Conversely, higher scores on the healthier patterns ('Traditional/health-conscious' and 'Vegetarian') were seen in girls and those whose mothers had higher levels of education. Of the five studies published to date exploring dietary patterns in adolescence, four examined possible associations with sociodemographic variables $^{(4,5,7,8)}$. Despite the differences in the patterns themselves and the variables that were examined, similar patterns of association were observed. In particular, the Spanish study ${ }^{(5)}$ reported an inverse association between their 'snacky' pattern (associated with sweets, salted snacks, cakes, biscuits and soft drinks) and maternal education level but a positive association was seen with the 'healthy' pattern. Girls were also more likely to adhere to the 'healthy' pattern. Similarly, Cutler $e t a l^{(8)}$ in their American population of 14-year-olds reported positive associations between socio-economic status (a composite score based primarily on parental educational level) and the 'vegetable' and 'fruit' patterns but negative associations with the 'sweet/salty snack food' and 'starchy food'. The Australian study of 12-18-year-olds ${ }^{(6)}$ reported that males were more likely to adhere to the 'high fat and sugar' pattern. However, no associations were evident with household income, the only sociodemographic factor examined.

Few other studies have examined the association between nutrient intakes and dietary patterns in adolescence. However, the associations we have demonstrated between the dietary pattern scores and nutrient intakes are virtually identical to those that we saw in the mothers of these children during pregnancy ${ }^{(29)}$. We have shown that the 'Traditional/health-conscious' pattern is nutrientrich with high positive correlations with many nutrients. The two patterns deemed to be less healthy, 'Processed' and 'Snacks/sugared drinks', showed little association with important nutrients but were positively associated with energy, fat and sugars. One other UK study has examined the associations between dietary patterns and nutrient intakes in slightly younger children (11-yearolds) ${ }^{(30)}$. All of these studies demonstrated positive nutrient profiles with the more 'healthy' dietary patterns and less desirable nutrient profiles with the more 'unhealthy' dietary patterns. The findings in that study were also similar to those reported here. Taken together these results add to the evidence that dietary patterns are a useful way of summarising diet, giving credibility to their representativeness of overall diet.

There are limitations to our study which warrant discussion. The use of two FFQ, one to each of the parent and child, covering slightly different foods and eating occasions, may have led to some bias; however, we felt that only using one source would have been likely to lead to different biases ${ }^{(6)}$. We were further constrained by the requirement to keep the questionnaire to the teenager as short as possible. Out of necessity, a number of assumptions were made when combining the two sets of dietary data; however, it is unlikely that recall bias is a major problem since we asked only about 'current' consumption. Missing data is an issue in the adjusted analyses but our sensitivity analysis showed that this did not influence the patterns found. We carried out a sensitivity analysis to explore the dietary patterns obtained from the sub-sample with complete sociodemographic and mode of eating data. The factor loadings obtained from the PCA 
were virtually identical to the original solution (data not shown). It could be argued that residual confounding is a problem in the adjusted analyses; however, these analyses were not designed to identify independent associations.

\section{Conclusion}

We have identified distinct dietary patterns evident at 13 years of age, using combined parental and child reported data, which are clearly socially patterned and associated with nutrient intakes in the way we would expect. These patterns will form the basis for future research into the longitudinal nature of dietary patterns from childhood into adolescence and their subsequent associations with health outcomes.

\section{Acknowledgements}

Sources of funding: This research was specifically funded by the World Cancer Research Fund (grant number 2009/23). The UK Medical Research Council, the Wellcome Trust and the University of Bristol provide core support for ALSPAC. Conflicts of interest: The authors declare no conflict of interest. Authors' contributions: P.M.E. collected the data, K.N. and P.M.E. conceived the study design, A.D.A.C.S. and K.N. performed the analysis, V.L.C. calculated the nutrient intakes and K.N. wrote the first draft of the manuscript. All authors approved the final version. This publication is the work of the authors and K.N. will serve as guarantor for the contents of this paper. Acknowledgements: The authors are extremely grateful to all of the families who took part in the study, the midwives for their help in recruiting them and the whole ALSPAC team, which includes interviewers, computer and laboratory technicians, clerical workers, research scientists, volunteers, managers, receptionists and nurses.

\section{References}

1. Mikkila V, Rasanen L, Raitakari OT et al. (2005) Consistent dietary patterns identified from childhood to adulthood: the Cardiovascular Risk in Young Finns Study. Br J Nutr 93, 923-931.

2. World Health Organization/Food and Agriculture Organization of the United Nations (2003) Diet, Nutrition and the Prevention of Chronic Diseases. Report of a Joint WHO/FAO Expert Consultation. WHO Technical Report Series no. 916. Geneva: WHO.

3. World Cancer Research Fund/American Institute for Cancer Research (2007) Food, Nutrition, Physical Activity, and the Prevention of Cancer: A Global Perspective. Washington, DC: AICR.

4. Kourlaba G, Panagiotakos DB, Mihas K et al. (2009) Dietary patterns in relation to socio-economic and lifestyle characteristics among Greek adolescents: a multivariate analysis. Public Health Nutr 12, 1366-1372.

5. Aranceta J, Perez-Rodrigo C, Ribas L et al. (2003) Sociodemographic and lifestyle determinants of food patterns in Spanish children and adolescents: the enKid study. Eur J Clin Nutr 57, Suppl. 1, S40-S44.
6. Ambrosini GL, O'Sullivan TA, de Klerk NH et al. (2011) Relative validity of adolescent dietary patterns: a comparison of a FFQ and $3 \mathrm{~d}$ food record. Br J Nutr 105, 625-633.

7. McNaughton SA, Ball K, Mishra GD et al. (2008) Dietary patterns of adolescents and risk of obesity and hypertension. J Nutr 138, 364-370.

8. Cutler GJ, Flood A, Hannan P et al. (2011) Multiple sociodemographic and socioenvironmental characteristics are correlated with major patterns of dietary intake in adolescents. J Am Diet Assoc 111, 230-240.

9. Livingstone MBE, Robson PJ \& Wallace JMW (2004) Issues in dietary intake assessment of children and adolescents. Br J Nutr 92, Suppl. 2, S213-S222.

10. Collins CE, Watson J \& Burrows T (2010) Measuring dietary intake in children and adolescents in the context of overweight and obesity. Int J Obes (Lond) 34, 1103-1105.

11. Ambrosini GL, Emmett PM, Northstone K et al. (2012) Identification of a dietary pattern prospectively associated with increased adiposity during childhood and adolescence. Int J Obes (Lond) 36, 1299-1305.

12. North K, Emmett P \& the ALSPAC Study Team (2000) Multivariate analysis of diet among three-year old children and associations with socio-demographic characteristics. Eur J Clin Nutr 54, 73-80.

13. Northstone K, Emmett P \& the ALSPAC Study Team (2005) Multivariate analysis of diet in children at four and seven years of age and associations with socio-demographic characteristics. Eur J Clin Nutr 59, 751-760.

14. Boyd A, Golding J, Macleod J et al. (2013) Cohort Profile: the 'children of the 90s' - the index offspring of the Avon Longitudinal Study of Parents and Children. Int J Epidemiol 42, 111-127.

15. Rogers IS, Emmett PM \& the ALSPAC Study Team (1998) Diet during pregnancy in a population of pregnant women in South West England. Eur J Clin Nutr 52, 246-250.

16. Gregory J, Foster K, Tyler H et al. (1990) The Dietary and Nutritional Survey of British Adults. London: HMSO.

17. Williams C, Birch EE, Emmett PM et al. \& the ALSPAC 'Children in Focus' Study Team (2001) Steroacuity at 3.5 years of age in children born full term is associated with prenatal and postnatal dietary factors; an early report from a population based study. Am J Clin Nutr 73, 316-322.

18. Holland B, Welch AA, Unwin ID et al. (1991) McCance $\mathcal{E}$ Widdowson's The Composition of Foods, 5th ed. Cambridge: The Royal Society of Chemistry.

19. Holland B, Unwin ID \& Buss DH (1992) Fruit and Nuts. First Supplement to 5th Edition of McCance \& Widdowson's The Composition of Foods. Cambridge: The Royal Society of Chemistry.

20. Chan W, Brown J, Lee SM et al. (1995) Meat, Poultry and Game. Fifth Supplement to 5th Edition of McCance \& Widdowson's The Composition of Foods. Cambridge: The Royal Society of Chemistry.

21. Gorsuch RL (1974) Factor Analyses. Philadelphia, PA: WB Saunders.

22. Kline P (1994) An Easy Guide to Factor Analysis. London: Routledge.

23. Cattell RB (1966) The scree test for the number of factors. Multivariate Behav Res 1, 245-276.

24. Northstone K \& Emmett PM (2008) Are dietary patterns stable throughout early and mid-childhood? A birth cohort study. Br J Nutr 100, 1069-1076.

25. Koh GA, Scott JA, Oddy WH et al. (2010) Exposure to noncore foods and beverages in the first year of life: results from a cohort study. Nutr Diet 67, 137-142.

26. Tak NI, te Velde SJ, de Vries JHM et al. (2006) Parent and child reports of fruit and vegetable intakes and related family environmental factors show low levels of agreement. J Hum Nutr Diet 19, 275-285. 
27. Reinaerts E, de Nooijer J \& de Vries NK (2007) Parental versus child reporting of fruit and vegetable consumption. Int J Behav Nutr Phys Act 4, 33.

28. Persson Osowski C, Fjellstrom C, Olsson U et al. (2012) Agreement between child and parent reports of 10- to 12year-old children's meal pattern and intake of snack foods. J Hum Nutr Diet 25, 50-58.
29. Northstone K, Emmett PM \& Rogers I (2008) Dietary patterns in pregnancy and associations with nutrient intakes. BrJ Nutr 99, 406-415.

30. Patel S, Murray CS, Simpson A et al. (2011) Dietary patterns of 11-year-old children and associations with nutrient intakes. J Hum Nutr Diet 24, 399-400.

\section{Appendix}

Food groups included in the analysis, indicating the source of each question

\begin{tabular}{|c|c|c|c|c|c|}
\hline \multirow[b]{2}{*}{ Food group } & \multirow[b]{2}{*}{ Mother's FFQ } & \multicolumn{4}{|c|}{ Teenager's FFQ } \\
\hline & & Packed lunch & School dinner & Bought food & All food \\
\hline Meat dishes & 1 & & 2 & & \\
\hline Cold meats & 1 & 1 & & & \\
\hline Poultry & 1 & & & & \\
\hline Meat sausages/burgers & 1 & & 1 & 1 & \\
\hline Meat pies/pasties & 1 & 1 & 1 & 1 & \\
\hline Offal & 1 & & & & \\
\hline Fish & 4 & & 1 & & \\
\hline Chicken/turkey in crispy coating & 1 & & & & \\
\hline White fish in breadcrumbs/batter & 1 & & 1 & & \\
\hline Eggs & 1 & & 1 & & \\
\hline Cheese & 1 & 1 & & & \\
\hline Rice & 1 & & 1 & & \\
\hline Pasta & 1 & & 1 & & \\
\hline Pizza & 1 & & 1 & 1 & \\
\hline Baked beans/tinned pasta & 2 & & 1 & & \\
\hline Fried food & 1 & & & & \\
\hline Raw fruit & 1 & 1 & 1 & 1 & 1 \\
\hline Tinned fruit & 1 & & & & \\
\hline Salad & 2 & 1 & 1 & & \\
\hline Peas & 1 & & 1 & & \\
\hline Sweetcorn & 1 & & 1 & & \\
\hline Green vegetables & 1 & & 1 & & \\
\hline Root vegetables & 2 & & 1 & & \\
\hline Meat substitutes & 2 & & & & \\
\hline Vegetarian pies/pasties & 1 & & 1 & & \\
\hline Nuts & 2 & & & & \\
\hline Pulses & 1 & & & & \\
\hline Potatoes & 1 & & 1 & & \\
\hline Roast potatoes & 1 & & 1 & & \\
\hline Chips & 2 & & 1 & 1 & \\
\hline Crisps & & 1 & & 1 & 1 \\
\hline Biscuits & & & & & 2 \\
\hline Crispbreads & 1 & & & & \\
\hline Chocolate/sweets & & & 1 & 1 & 2 \\
\hline White bread & 1 & & & & \\
\hline Other bread & 1 & & & & \\
\hline Butter/margarine & 1 & & & & \\
\hline Non-homemade sandwiches & & 1 & 1 & 1 & \\
\hline Lunchbox snacks & 1 & 1 & & & \\
\hline Yoghurt/fromage frais & 1 & & 1 & & \\
\hline Puddings & 1 & & 1 & & \\
\hline Milk puddings/custard/mousse & 2 & & 1 & & \\
\hline Ice cream & 1 & & & & \\
\hline Ice lollies & 1 & 1 & & & \\
\hline Cakes/buns & 1 & & 1 & & \\
\hline Ketchup/brown sauce & 1 & & & & \\
\hline Mayonnaise/salad cream/dressing & 1 & & & & \\
\hline Oat-based cereal & 1 & & & & \\
\hline Bran-based cereal & 1 & & & & \\
\hline Other cereal & 1 & & & & \\
\hline Cereal bars & 1 & & & & \\
\hline Full-fat milk to drink & 1 & & & & \\
\hline Other milk to drink & 1 & & & & \\
\hline Flavoured milk drinks & 1 & & & & 1 \\
\hline Fruit juice & 1 & & & & 1 \\
\hline Squash & & & & & 1 \\
\hline Water & 2 & & & & 1 \\
\hline Fizzy drinks & & & & & 2 \\
\hline Tea/coffee & 2 & & & & \\
\hline Herbal tea & 1 & & & & \\
\hline Alcohol & 4 & & & & \\
\hline
\end{tabular}

The numbers show how many questions contributed to each food group from each questionnaire. 